\title{
Assessment of risk factors and its fetal outcome of preterm birth: in rural tertiary care hospital, Karad, Maharashtra
}

\author{
Corresponding author: \\ Dhirajkumar A. Mane, Statistician, \\ Directorate of Research Krishna \\ Institute of Medical Sciences \\ "Deemed To Be University", \\ Karad, Maharashtra, India \\ e-mail: dhirajmane123@gmail.com
}

Medical Research Journal 2019; Volume 4, Number 2, 80-84 10.5603/MRJ.a2019.0019 Copyright (C) 2019 Via Medica ISSN 2451-2591

\begin{abstract}
Background: Preterm birth is an alarming cause of complication in pregnancy that leads to an immense burden for imitation of children to their householders and health care providers. The present study was to find out the functional relationship of preterm birth (PTB) and its study parameters at the Krishna Hospital and Medical Research Centre Karad, Maharashtra from 2016-17. In SPSS (20.0), IBM, INDIA, multiple regression method was used to analyze the results.

Methods: This was cross-sectional study done at rural tertiary care hospital, Karad. The examination was done in the ob-gyn. ward and various details were collected in the form of the questionnaire at present that ward with support of oral discussion of that patient.

Results: Age and many more demographic variables were significantly associated with its fetal outcome of preterm birth. Also, it seems that pregnancy-induced hypertension, placenta diameter; numbers of meals, delivery mode, and those reasons were effective measures of risk factors of assessment of preterm birth. Conclusions: All the variables analyzed in this study were the part of the determinants of PTB needs to check time to time during the period of pregnancy. Heath care providers still need to take efforts for pregnancy-induced hypertension, placenta diameter.

Key words: fetal outcome, preterm delivery, preterm risk, PTB.
\end{abstract}

Med Res J 2019; 4 (2): 80-84

\section{Introduction}

PTB is the theory of gestational weeks. The early interruption of the course of pregnancy can lead to structural and anatomic changes of the central nervous system. It is more likely measured into various determinants like mortality and morbidity of neonates: mild, very pre-term and extremely childhood disability and remains one of the most serious problems in obstetrics [1-3] Approximately in developing countries have $>90 \%$ of the world's PTBs, of which $60 \%$ are in South Asian and African countries, and $12.3 \%$ of PTBs are from sub-Saharan African countries [4]. 1.2 million PTBs occur per year in developed countries, and among these more than half a million deliveries take place in the US [5].

PTB is the second-leading cause of mortality in children aged $<5$ years, after pneumonia. Complications of PTBs are the largest cause of neonatal deaths. Globally, more than 3.1 million neonatal deaths occur every year, and about $35 \%$ of deaths are due to prematurity of newborns [6]. in developing countries, about $99 \%$ of immature babies death within the early days of life [7]. Moreover, more than 3 million annual neonatal deaths are directly related to stillbirth and PTB. In addition to this mortality, PTB is also associated with long term disabilities in surviving neonates [8].

Since, the last twenty years despite major preventive efforts, the incidence of PTB has remained constant at about $5-10 \%$ of live births in most countries [9-11]. Approximately $12.7 \%$ of births are preterm and $2 \%$ are less than 32 weeks. It is estimated that 70 to $80 \%$ of PTBs occur spontaneously. The remaining 20 to $30 \%$ of PTBs are due to intervention for maternal or fetal problems $[12,13]$. 


\section{Aim and objectives}

- To assess the risk factors of preterm singleton birth

- To assess the fetal outcome of preterm singleton birth

\section{Material and methods}

Methodology of research indicates the general pattern for organizing the procedure for the empirical study of obtaining valid and reliable data for the problem under investigation.

Sources of data: Mothers who are delivered (before 37 weeks of gestation) at maternity wards of Krishna Hospital, Karad.

Research Approach: In view of the nature of the statement of a problem for the study, the descriptive approach will be appropriate for the study.

Research design: The cross-sectional study design was used for the present study.

Variables of the study: In this study, the variables were a risk factor of preterm birth. Such as Age, socioeconomic category, type of diet, previous history of preterm delivery, height, weight before delivery, the pre-pregnancy weight of the mother, Body mass index, no of antenatal checkup visit, Drug used during pregnancy, Antenatal morbidity, Gestational age etc.

Research setting: The study was conducted at the maternity ward of Krishna Hospital, Karad District Satara.

Population: Population was the entire aggregation of cases in which a researcher is interested. In the present study, the population comprises mothers who are delivered before 37 weeks of gestation in maternity wards of Krishna Hospital, Karad.

Sample: A sample was a portion of the entire population that represents a subset of the entire population elements. For present study samples were mothers delivered before 37 weeks of gestation in maternity wards of Krishna Hospital, Karad available at the time of data collection.

Sample size: According to antenatal check-ups observed in preterm and term deliveries

$$
\begin{aligned}
\mathrm{n} & =\frac{\left(\mathrm{SD}_{1}{ }^{2}+\mathrm{SD}_{2}{ }^{2}\right)\left(\mathrm{Z}_{1-} \cdot / 2+\mathrm{Z}_{1}-\beta\right)^{2}}{\left(\mathrm{X}_{1-} \mathrm{X}_{2}\right)^{2}} \\
& =\frac{\left(4.12^{2}+3.89^{2}\right)(1.96+0.84)^{2}}{(6.9-8.5)^{2}}=99
\end{aligned}
$$

So, here I considered 100 preterm deliveries were included in the present study.

Inclusion criteria:

- The mothers delivered before 37 weeks of gestations and admitted in the maternity ward of Krishna Hospital, Karad.

- Those who were willing to participate during the period of data collection.
Exclusion criteria:

- Mothers admitted for other obstetrical conditions except for delivery.

- Mothers who were in critical condition (developed complications) after delivery.

Methods of data collection

Sampling Technique: Randomization sampling technique was used for the present study.

Tools for Data Collection: Structured interview schedule for assessing risk factors of preterm births was used for the collection of data. The Structured interview schedule will be developed in 2 sections.

Section I: Demographic variables.

Section II: a Risk factor of preterm birth.

Ethical Clearance/Permissions for Collection of Data: The researcher was obtaining ethical clearance from Institutional Ethical Committee of KIMSDU and permission taken by Medical Director of Krishna Hospital, head of the department of Obstetrics and Gynecology, Dean KINS, Director of Nursing Services and from the ward supervisor.

The steps used for data collection as follows:

- Investigator finds out related subjects and notifies about objectives and steps of study and takes informed consent.

- Data was collected by using the interview method and referring the case record of each mother.

- Data was analyzed and interpreted by using descriptive and inferential statistics.

\section{Statistical/Data analysis}

- The analyzed data was presented in the form of tables, diagrams, and graphs based on findings. For comparing study variables with demographic variables chi-square analysis was used also comparison was done by using the unpaired t-test. SPSS 20.0, IBM, INDIA, Software was used for analyzing data. If $p<0.05$ then there was statistical significance.

\section{Results and discussion}

In this study, it was revealed that the classification of various demographic variables and birth outcomes. Here we assess age, religion, education, socio-economic status, type of family, habits, residency, type of diet, employed during pregnancy, PTD, no. of abortions etc. We found that there was statistical significance $(p<0.05)$ of fetal outcome among the demographic variables like age, religion, socio-economic status, type of family, habits, residency, \& PTD. Also, we not able to found a significant association between education, type of diet, employed during pregnancy, parity, previous abortions and its fetal outcome (Tab. 1). 
Table 1. Association between demographic variables and fetal outcome

\begin{tabular}{|c|c|c|c|c|c|}
\hline Demographic variables & No. of mothers & LBW & NBW & $\begin{array}{c}\text { Chi-square } \\
\chi^{2}\end{array}$ & P-value \\
\hline \multicolumn{6}{|l|}{ Age (in yrs.) } \\
\hline $20-22$ & 34 & 29 & 5 & 19.704 & $<0.0001$ * \\
\hline $23-25$ & 41 & 30 & 11 & & \\
\hline $26-28$ & 25 & 8 & 17 & & \\
\hline \multicolumn{6}{|l|}{ Religion } \\
\hline Hindu & 57 & 47 & 10 & 23.205 & $<0.0001^{*}$ \\
\hline Muslim & 27 & 17 & 10 & & \\
\hline Christian & 16 & 3 & 13 & & \\
\hline \multicolumn{6}{|l|}{ Education } \\
\hline Illiterate & 8 & 7 & 1 & 3.37 & 0.338 \\
\hline Primary & 3 & 1 & 2 & & \\
\hline Secondary & 62 & 40 & 22 & & \\
\hline Graduate \& Above & 27 & 19 & 8 & & \\
\hline \multicolumn{6}{|l|}{ Socio-economic status } \\
\hline$\geq 32,050$ & 28 & 10 & 18 & 17.749 & $0.0005^{\star}$ \\
\hline $12,020-16,019$ & 52 & 40 & 12 & & \\
\hline $8,010-12,019$ & 19 & 16 & 3 & & \\
\hline$\leq 4,810-8,009$ & 1 & 1 & 0 & & \\
\hline \multicolumn{6}{|l|}{ Type of family } \\
\hline Nuclear & 34 & 28 & 6 & 12.168 & $0.0023^{\star}$ \\
\hline Joint & 51 & 26 & 25 & & \\
\hline Extended & 15 & 13 & 2 & & \\
\hline \multicolumn{6}{|l|}{ Habits } \\
\hline Alcoholism & 10 & 9 & 1 & 15.956 & $0.0012^{*}$ \\
\hline Tobacco Chewing & 30 & 27 & 3 & & \\
\hline Smoking & 4 & 2 & 2 & & \\
\hline Other & 56 & 29 & 27 & & \\
\hline \multicolumn{6}{|l|}{ Residency } \\
\hline Rural & 50 & 39 & 11 & 5.473 & $0.0193^{*}$ \\
\hline Urban & 50 & 28 & 22 & & \\
\hline \multicolumn{6}{|l|}{ Type of diet } \\
\hline Pure Veg. & 15 & 11 & 4 & 0.3201 & 0.8521 \\
\hline Mixed Diet & 85 & 56 & 29 & & \\
\hline \multicolumn{6}{|l|}{ Employed during pregnancy } \\
\hline Yes & 18 & 13 & 5 & 0.2708 & 0.6028 \\
\hline No & 82 & 54 & 28 & & \\
\hline \multicolumn{6}{|l|}{ Parity } \\
\hline Nulliparous & 84 & 56 & 28 & 0.02638 & 0.871 \\
\hline Multiparous & 16 & 11 & 5 & & \\
\hline \multicolumn{6}{|l|}{ PTD } \\
\hline Yes & 98 & 67 & 31 & 4.143 & $0.0418^{*}$ \\
\hline No & 2 & 0 & 2 & & \\
\hline \multicolumn{6}{|l|}{ No. of previous abortion } \\
\hline Yes & 86 & 57 & 29 & 0.1444 & 0.7039 \\
\hline No & 14 & 10 & 4 & & \\
\hline
\end{tabular}

*Significant when $p<0.05$ LBW — Lower Birth Weight; PTD — Preterm Delivery; NBW — Normal Birth Weight 
Table 2. Association between study variables and fetal outcome

\begin{tabular}{|c|c|c|c|c|c|c|}
\hline Study variables & No. of mothers & $\begin{array}{l}\text { LBW } \\
(\%)\end{array}$ & $\begin{array}{c}\text { NBW } \\
(\%)\end{array}$ & $\begin{array}{c}\text { Chi-square } \\
\chi^{2}\end{array}$ & P-value & $\begin{array}{l}\text { Odds ratio } \\
\text { (C. I) }\end{array}$ \\
\hline \multicolumn{7}{|l|}{ Placenta diameter } \\
\hline$<18 \mathrm{~cm}$ & $47(47)$ & $40(40)$ & $7(7)$ & \multirow[t]{3}{*}{11.64} & \multirow[t]{3}{*}{0.0006} & \multirow{3}{*}{$\begin{array}{c}0.1817 \\
(0.069-0.47)\end{array}$} \\
\hline$\geq 18 \mathrm{~cm}$ & $53(53)$ & $27(27)$ & $26(26)$ & & & \\
\hline Total & $100(100)$ & $67(67)$ & 33(33) & & & \\
\hline \multicolumn{7}{|l|}{ Body Mass Index } \\
\hline$\leq 25$ & 43 & $35(35)$ & $8(8)$ & \multirow[t]{3}{*}{5.974} & \multirow[t]{3}{*}{0.0145} & \multirow{3}{*}{$\begin{array}{c}0.2926 \\
(0.1155-0.7412)\end{array}$} \\
\hline$>25$ & 57 & $32(32)$ & $25(25)$ & & & \\
\hline Total & 100 & $67(67)$ & $33(33)$ & & & \\
\hline \multicolumn{7}{|c|}{ No. of meals (in one day) } \\
\hline$\leq 2$ & $33(33)$ & $29(29)$ & $4(4)$ & \multirow[t]{3}{*}{17.327} & \multirow[t]{3}{*}{$<0.0001$} & \multirow{3}{*}{$\begin{array}{c}0.099 \\
(0.03126- \\
0.3137)\end{array}$} \\
\hline$\geq 3$ & $67(67)$ & $37(37)$ & 29(29) & & & \\
\hline Total & $100(100)$ & $67(67)$ & $33(33)$ & & & \\
\hline \multicolumn{7}{|c|}{ Pregnancy-induced hypertension } \\
\hline Yes & $52(52)$ & $41(41)$ & $11(11)$ & \multirow[t]{3}{*}{5.805} & \multirow[t]{3}{*}{0.016} & \multirow{3}{*}{$\begin{array}{c}0.3171 \\
(0.1322-0.7606)\end{array}$} \\
\hline No & $48(48)$ & $26(26)$ & $22(22)$ & & & \\
\hline Total & $100(100)$ & $67(67)$ & 33(33) & & & \\
\hline \multicolumn{7}{|c|}{ Gestational diabetes mellitus } \\
\hline Yes & $68(68)$ & $44(44)$ & $24(24)$ & \multirow[t]{3}{*}{0.2335} & \multirow[t]{3}{*}{0.6289} & \multirow{3}{*}{$\begin{array}{c}1.394 \\
(0.5570-3.489)\end{array}$} \\
\hline No & $32(32)$ & $23(23)$ & $9(9)$ & & & \\
\hline Total & $100(100)$ & $67(67)$ & 33(33) & & & \\
\hline
\end{tabular}

Table 3. Relationship between mode of delivery and fetal outcome

\begin{tabular}{lccccc}
\hline Mode of delivery & No. of mothers & LBW & NBW & Chi-Square & P-value \\
\hline Spontaneous vaginal delivery & $26(26)$ & $20(20)$ & $6(6)$ & 8.256 & 0.041 \\
assisted vaginal delivery & $26(26)$ & $19(19)$ & $7(7)$ & & \\
elective LSCS & $22(22)$ & $9(9)$ & $13(13)$ & & \\
emergency LSCS & $26(26)$ & $18(18)$ & $8(8)$ & & \\
Total & $100(100)$ & $67(67)$ & $33(33)$ & & \\
\hline
\end{tabular}

Also some of the variables which were previously found as risk factors of the preterm birth. Here I had considered placenta diameter, body mass index, no. of meals (in a day), pregnancy-induced hypertension and gestational diabetes mellitus. It was observed that meal numbers, placenta diameter, pregnancy-induced hypertension were significantly associated with PTB. But, there was no such role of body mass index. Also by odds ratio, we had stated that there was a definite role of these parameters to overcome the risk of PTB (Tab. 2)

We had to assess the role of mode of delivery in PTB and it was observed significant association $(p<0.05)$ between mode of delivery and fetal outcome (Tab. 3).

\section{Discussion}

There were lots of studies was done in this same concept previously, but this study focused on apart from various parameters identified those determinants which influenced to identified risk factors of PTB. In various studies, pregnancy-induced hypertension was found to be significantly associated with PTB outcome variables [14-16]. In the current study, we observed a similar scenario in which pregnancy-induced hypertension was significantly associated with all categories of preterm delivery also it seems the majority of study variables were significantly associated with PTB except BMI. This 
study revealed the same situation as any maternal age. It is, therefore, possible to consider advanced maternal age as a direct link or a risk marker through its association with age-dependent confounders for PTD. The present study was shown that PTB was significantly associated with age, religion, socio-economic status, type of family, habits, residency, and PTD delivered in the study period. Also, here we found that placenta diameter, pregnancy-induced hypertension were negatively correlated with birth outcome. So many studies were done in the same situation but in this environment very rare studies done on this topic so it was needed to take review on the same situation which really helps for the community.

\section{Conclusion}

This study dataset revealed that PTB remains high in India and findings suggest the same situation in many more developing countries. This study results revealed that there are both modifiable and non-modifiable factors that furnish as PTB in the study group of individuals. As reliable on this study data and also the same type of studies was done in related study area I advise that maximum pregnancies are interpret as a huge risk by the health care providers in Western Maharashtra. It is needed to work on before birth care in order to substantially minimize unfavourable birth conclusion such as PTB. It is too essential to establish in the early period of pregnancy, a follow-up target system between health service providers, private practitioners, ASHA sevika, PHC's and family support for specialist doctors/hospitals to ensure that each and every woman gets quality prenatal as well as antenatal care.

\section{Implication}

\section{Nursing practice, education, administration and research}

The midwives have a vital role in providing safe and effective nursing care and education to prevent preterm birth. Such would be done by motivating the nurse midwives to (a) have in-depth knowledge about risk factors of PTB and known to prevent that by giving the education to antenatal women. Nurse educator needs to provide health education to women in pregnancy which will reduce the risk of preterm birth. Educate the students about the various risk factor of preterm birth. Practical sessions also provided to give comprehensive care for the intro natal mothers. Encourage the students for effective utilization of research-based practice. Nurse Manager can plan for antenatal classes as well as video-assisted programs on OPD basis in order to prevent preterm birth.

Nursing Managers and administrators need to facilitate the utilization of research-based nursing care aspects in day-to-day practices to formulate policies and make necessary changes in the healthcare delivery system in the hospitals.

\section{References}

1. Lumley J. Defining the problem: the epidemiology of preterm birth. BJOG. 2003; 110 Suppl 20: 3-7, doi: 10.1046/j.1471-0528.2003.00011.x, indexed in Pubmed: 12763104.

2. MOUTQUIN J. Classification and heterogeneity of preterm birth. BJOG: An International Journal of Obstetrics and Gynaecology. 2003; 110: 30-33, doi: 10.1016/s1470-0328(03)00021-1.

3. Lawn JE, Cousens S, Zupan J, et al. Lancet Neonatal Survival Steering Team. 4 million neonatal deaths: when? Where? Why? Lancet. 2005; 365(9462): 891-900, doi: 10.1016/S0140-6736(05)71048-5, indexed in Pubmed: 15752534

4. International Statistical Classification of Diseases and Related Health Problems. Encyclopedia of Clinical Neuropsychology. 2011: 1347-1347, doi: 10.1007/978-0-387-79948-3 3055.

5. United Nations Children's Fund. The State of the sWorld's Children 2009: Maternal and Newborn Health.

6. Blencowe H, Cousens S, Chou D, et al. Born Too Soon Preterm Birth Action Group. Born too soon: the global epidemiology of 15 million preterm births. Reprod Health. 2013; 10 Suppl 1: S2, doi: 10.1186/17424755-10-S1-S2, indexed in Pubmed: 24625129.

7. Menon R. Preterm birth: a global burden on maternal and child health. Pathog Glob Health. 2012; 106(3): 139-140, doi: 10.1179/204777312 X13462106637729, indexed in Pubmed: 23265368.

8. Lawn JE, Gravett MG, Nunes TM, et al. GAPPS Review Group. Global report on preterm birth and stillbirth (1 of 7): definitions, description of the burden and opportunities to improve data. BMC Pregnancy Childbirth. 2010; 10 Suppl 1: S1, doi: 10.1186/1471-2393-10-S1-S1, indexed in Pubmed: 20233382

9. Wen SWu, Smith $\mathrm{G}$, Yang Q, et al. Epidemiology of preterm birth and neonatal outcome. Semin Fetal Neonatal Med. 2004; 9(6): 429-435, doi: 10.1016/j.siny.2004.04.002, indexed in Pubmed: 15691780.

10. Bibby E, Stewart A. The epidemiology of preterm birth. Neuro Endocrinol Lett. 2004; 25 Suppl 1: 43-47, indexed in Pubmed: 15735585.

11. Zeitlin J, Bucourt M, Rivera L, et al. Preterm birth and maternal country of birth in a French district with a multiethnic population. BJOG. 2004; 111(8): 849-855, doi: 10.1111/j.1471-0528.2004.00184.x, indexed in Pubmed: 15270935.

12. Carey JC, Gibbs RS. Preterm labor and post- term delivery. In: Gibbs RS, Karlan BY. 2005; 112: 430-7.

13. Lee KG. Identifying the high-risk newborn and evaluating gestational age, rematurity, ost maturity, large-for-gestational-age, and small-for-gestational-age infants. In: Cloherty JP, Eichenwald EC, Stark AR, editors. of neonatal care. 6th ed. New York: Williams \& Wilkins; 2008. p. : 42-58.

14. Di Renzo GC, Giardina I, Rosati A, et al. Italian Preterm Network Study Group. Maternal risk factors for preterm birth: a country-based population analysis. Eur J Obstet Gynecol Reprod Biol. 2011; 159(2): 342-346, doi: 10.1016/j.ejogrb.2011.09.024, indexed in Pubmed: 22036591.

15. Assunção PL, Novaes HM, Alencar GP, et al. [Factors associated with preterm birth in Campina Grande, Paraíba State, Brazil: a case-control study]. Cad Saude Publica. 2012; 28(6): 1078-1090, indexed in Pubmed: 22666812

16. Spiegler J, Stichtenoth G, Weichert J, et al. German Neonatal Network, GNN. Pregnancy risk factors for very premature delivery: what role do hypertension, obesity and diabetes play? Arch Gynecol Obstet. 2013; 288(1): 57-64, doi: 10.1007/s00404-013-2739-6, indexed in Pubmed: 23400353 